\title{
CRISPR-Cas, a robust gene-editing technology in the era of modern cancer immunotherapy
}

\author{
Seyed Mohammad Miri ${ }^{1}$, Elham Tafsiri ${ }^{2}$, William Chi Shing Cho ${ }^{3}$ and Amir Ghaemi ${ }^{4^{*}}$ (]
}

\begin{abstract}
Cancer immunotherapy has been emerged as a promising strategy for treatment of a broad spectrum of malignancies ranging from hematological to solid tumors. One of the principal approaches of cancer immunotherapy is transfer of natural or engineered tumor-specific T-cells into patients, a so called "adoptive cell transfer", or ACT, process. Construction of allogeneic T-cells is dependent on the employment of a gene-editing tool to modify donor-extracted T-cells and prepare them to specifically act against tumor cells with enhanced function and durability and least sideeffects. In this context, CRISPR technology can be used to produce universal T-cells, equipped with recombinant T cell receptor (TCR) or chimeric antigen receptor (CAR), through multiplex genome engineering using Cas nucleases. The robust potential of CRISPR-Cas in preparing the building blocks of ACT immunotherapy has broaden the application of such therapies and some of them have gotten FDA approvals. Here, we have collected the last investigations in the field of immuno-oncology conducted in partnership with CRISPR technology. In addition, studies that have addressed the challenges in the path of CRISPR-mediated cancer immunotherapy, as well as pre-treatment applications of CRISPR-Cas have been mentioned in detail.
\end{abstract}

Keywords: Cancer immunotherapy, CRISPR-Cas, Cas9, TCR T-cell, CART-cell, Allogeneic T-cell

\section{Background}

According to statistics, the appearance of about 18.1 million newfangled cancer victims and 9.6 million cancerrelated fatalities just in 2018 is entirely self-explanatory of the importance of developing more efficient cancer therapy strategies [1]. Besides the well-known approaches of cancer therapy such as chemotherapy, radiotherapy, surgery, as well as the latest methods such as oncolytic virotherapy, harnessing the immune system against cancer cells has been developed [2,3]. Engineered T-cell's anti-cancer properties have expanded the application of immunotherapy from viral infections to cancer treatment

*Correspondence: ghaem_amir@yahoo.com; a_ghaemi@pasteur.ac.ir

${ }^{4}$ Department of Virology, Pasteur Institute of Iran, Tehran, P.O.Box: 1316943551, Iran

Full list of author information is available at the end of the article
[4]. Adoptive cell transfer (ACT) cancer immunotherapy can be done through deployment of three different immunogenic constructs including tumor-infiltrating lymphocytes (TILs), T-cell receptor (TCR) T-cells, and engineered chimeric antigen receptor (CAR) T-cells [5]. To achieve desired CAR T-cells or to modify TCR T-cells, incorporation of a gene-engineering tool is needed. Clustered regularly interspaced short palindromic repeats (CRISPR) in association with Cas nuclease stands out from other gene-editing methods, such as zinc finger nucleases (ZFNs) and transcription activator-like effector nucleases (TALENs), due to simplicity, high fidelity, and multi-target editing potential [6]. The role of CRISPR is not limited to therapeutic purposes. CRISPR screening technology is applied to find novel immunotherapy targets and other unknown genetic participants in immune response pathways. The outcome of those screening trials 
constitute an integral part of future cancer immunotherapy approaches with improved fidelity and efficiency, as well as minimal off-targeting and side-effect problems [7].

To address the chronic malignancy of cancer, many ongoing pre-clinical and clinical trials have been applying constantly. In this article, we focused on an exclusive zone of these trials in which adoptive immunotherapy intersects with a sophisticated gene-editing tool, CRISPR-Cas technology. However, a huge tendency toward utilization of this combination has been aroused some ethical controversies [8]. Humanitarian health concerns, as well as other limitations associated with CRISPR-assisted cancer immunotherapy, and the attempts to bypass these challenges have not been overlooked from our critical viewpoint.

\section{Cancer immunotherapy, from genesis to modern CARs}

As it is obvious from the phraseology, cancer immunotherapy stands for all cancer therapeutic procedures in co-operation with the immune system. One of the earliest reports of immune system's triumph against cancer backs to 1890, when William Coley observed that some cancer patients with skin infection experience better condition than those without infections, a phenomenon that later determined was due to the immune responses elicited by bacterial infection [9]. Immunological-assisted cancer therapy remained a controversial subject for decades until 1965, when leukemia cell's regression of a patient was reported following bone marrow transplantation in response to adopted immune cell function against tumor cells. The phrase "adoptive immunotherapy" was originated from that case. Later, it was elucidated that T-cells accompanied by natural killer (NK) cells had the principal role in that observed phenomenon [10].

Immunotherapeutic approaches can be classified into two main categories (1) indirect modification of T-cell's regulatory elements or immunologically active proteins like interferons, and (2) direct ex vivo manipulation and restoration of T-cells or implanting engineered universal T-cells [4]. Initial cancer immunotherapy trials have been majorly performed by using some antibodies such as ipilimumab (CTLA-4 targeting antibody), anti-programmed cell death 1 (anti-PD-1), anti-programmed death-ligand 1 (anti-PD-L1), and anti 4-1BB [11], alongside with the administration of cancer vaccines like trastuzumab emtansine for advanced her $2^{+}$breast cancer [12], NCSDNA E7 vaccine against cervical cancer [13], and atezolizumab for non-small cell lung cancer [14]. Afterwards, the development of novel combinatorial methods exhibited more reliable and efficient anti-tumor responses in comparison with their separate application [15]. In this context, administration of HPV16 E7 DNA vaccine adjuvanted with anti-PD-1 and secondary lymphoid-tissue chemokine (CCL21 or SLC) or the toll like receptor agonist and $\alpha$-Galactosylceramide in tumor-bearing mice models resulted in both tumor regression and tumor growth suppression $[16,17]$.

With the advent of synthetic biology and novel genetherapy techniques and in the light of more efficient gene delivery tools, cancer immunotherapy has shifted into a modern era [18], where engineered autologous or adopted T-cells are implanted into the patient's body, a cancer immunotherapy method called adoptive cell therapy (ACT). ACT is followed through three major methods including (1) using TILs, (2) modifying TCR T-cells, and (3) engineering CAR T-cells [19].

TIL contains the biopsy and extraction of T lymphocytes present in cancerous tissues, followed by culturing and activation of potentially involved T-cells. Using the autologous inactive yet potential T-cells was the initial idea however, the achievement to not only adequate but also appropriate and healthy tumor-specific T-cells is not always possible. Preparation of efficient T-cells by this method is time-consuming and together with intolerability against tumor changes make its application limited mostly to melanoma [20].

On the other hand, equipment of donor-independent $\mathrm{T}$-cells with either surface antigen receptors (in CAR) or recombinant MHC-dependent antigen receptors (in TCR), is a further step to expand the application of cancer immunotherapy to cure solid tumors besides hematological malignancies (Fig. 1) [21]. Native T-cell receptors harness TCR $\alpha$ - and $\beta$-chains of tumor-specific antigen as the wild type recognition element (Fig. 1b), however, the application of recombinant TCR T-cells is restricted due to their MHC-dependent tumor-independent behavior, i.e., the high probability of off-target activities [22].

Despite TCR, CAR T-cell is profiting from MHC-independent design, by which it can recognize a wide variety of cell surface antigens (protein, carbohydrate or glycolipid) [23]. Recombinant CAR is constructed by fusing extracellular single chain antibody (typically single-chain fragment antibody $\mathrm{scFv}$ ) with intracellular signaling domains through the hinge and transmembrane domains [24]. Evolutionary pathway of CARs consists of four subsequent generations (Fig. 1B). The first and simplest version of CARs utilized TCR-CD3 $\zeta$ or FCR- $\zeta$ as intracellular signaling part. In-vivo malfunction of this generation due to lack of costimulatory signaling domains pushed the scientists to armor CARs with responding proteins such as CD28 or 4-1BB (CD137) to give birth to the 2nd generation of CARs. The 3rd generation of CARs was simultaneously equipped with two costimulatory domains [25]. Recently, the 4th generation of CARs, 


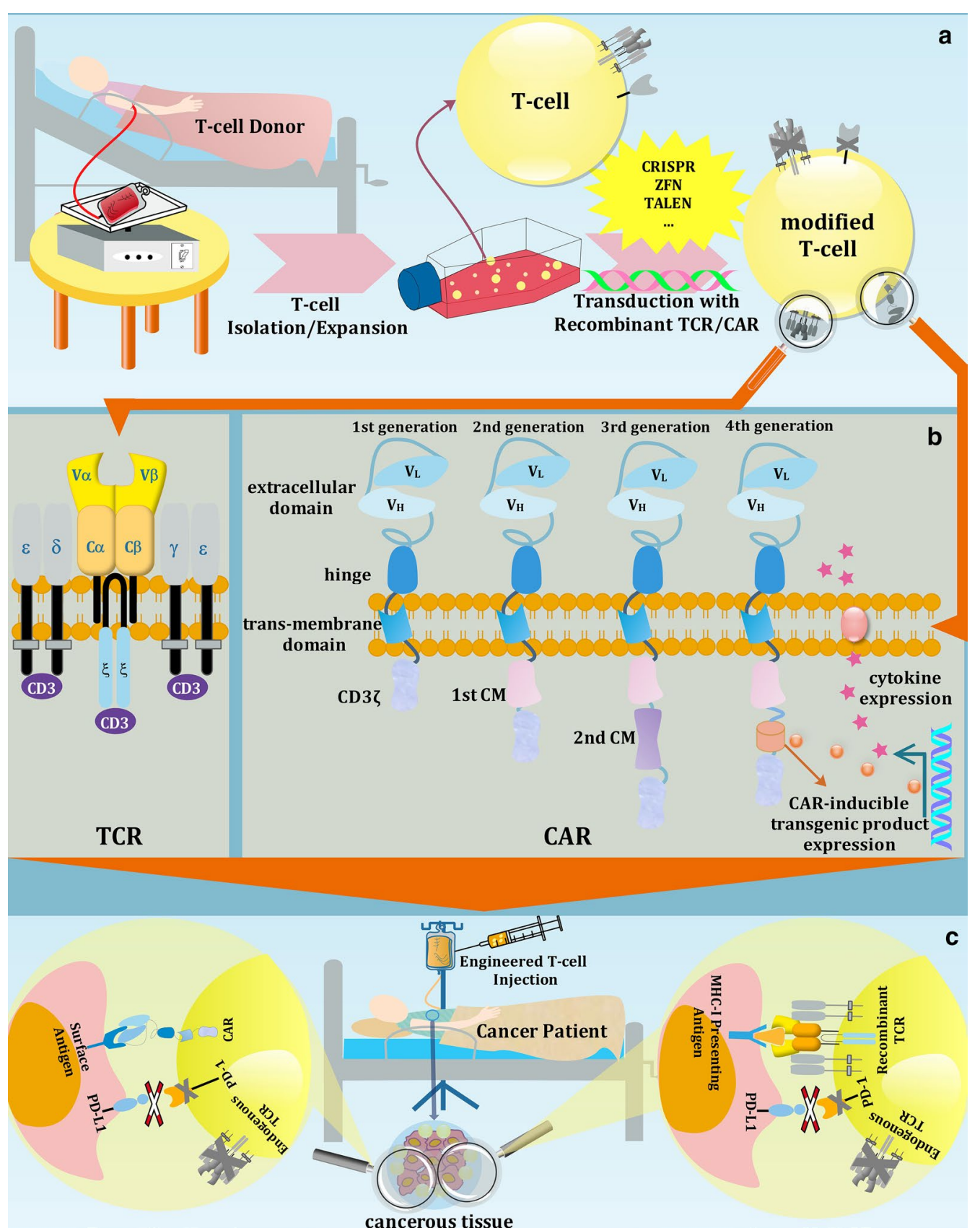

Fig. 1 TCR and CART-cell cancer immunotherapy. a Schematic overview of CAR and TCR T-cell construction. Isolation and expansion of human T Lymphocytes (extracted from healthy donor blood) are followed by modification of T-cells by gene-editing tools (CRISPR, ZFN,...) and transduction of T-cells with transgenic TCR or CAR gene constructs. b TCR and four generations of CAR structure. (CM: co-stimulatory molecule, Ca: constant a-chain, CB: constant B-chain, Va: variable a-chain, VB: variable B-chain, VL: variable light chain, VH: variable heavy chain) c Engineered TCR and CAR T-cells employment in the treatment of candidate patient. TCR identifies MHC-I presenting antigens and CAR targets tumor cell surface antigens

namely CAR-modified T-cell (TRUCK T-cell), with improved expansion and persistence to the immunosuppressive tumor environment has been developed. Potent impact of some cytokines and ligands such as IL-12 and CD40 ligand on the enhancement of T-cell activation was the initial sparkle for the genesis of this late generation of CARs [26].

In order to enhance the tumor-specific antigen recognition by CAR T-cells and to inhibit misleading of engineered CAR T-cells toward tumor-like 
antigen-presenting healthy cells, Kloss et al. simultaneously equipped CAR T-cells with two distinct antigenspecific receptors, one against prostate stem cell antigen (PSCA) as conventional CAR receptor and the other against prostate-specific membrane antigen (PSMA) as a chimeric costimulatory receptor, and constructed dualtargeting CAR T-cells specialized against $\mathrm{PSCA}^{+} \mathrm{PSMA}^{+}$ prostate tumor cells, succeeded to efficiently reduce the risk of on-target off-tumor activity of CAR T-cell therapy in vivo [27].

The initial promising outcomes regarding CAR T-cell therapy come from targeting CD19 receptor on the surface of $\mathrm{CD} 19^{+} \mathrm{B}$ cell tumors [28]. The efficacy of CAR immunotherapy has been evaluated against some models of B cell cancer including malignant acute lymphoid leukemia (ALL), non-Hodgkin lymphoma, and chronic lymphocytic leukemia, and some of them have gotten FDA approval for clinical exploitation. Expansion of CAR application to the treatment of $\mathrm{CD}^{-} 9^{-}$hematological malignancies as well as pernicious solid tumors has been being under intensive study $[29,30]$.

\section{CRISPR, the treasure trove of gene-editing technologies}

Clustered Regularly Interspaced Short Palindromic Repeats accompanied by Cas nuclease protein (CRISPRCas) is defined as the chief beneficiary of RNA-guided adaptive immune system of prokaryotic cells. The first CRISPR locus was initially deciphered in 1987, but its ability to provoke adaptive immunity in the presence of Cas enzyme hadn't been determined until 2005, and since then, the revolutionary impact of CRISPR-Cas system on genetic-based manipulation strategies has begun to develop gradually [31]. Diverse types of CRISPR system have been discovered among bacteria and archae. Until now, 2 classes (based on evolved Cas proteins), 6 types and over 35 subtypes (corresponding to signature genes) have constituted the members of CRISPR big family (Table 1) [32-37].

Typically, countering against foreign invasions caused by bacteriophages and plasmids by means of CRISPR machinery is pursued in three phases adaptation, expression, and interference. During the phase one, chromosomal integration of immature fragments of foreign DNA into the spacer region of CRISPR reconstitutes a novel spacer, acting as a genetic barcode in prospective attacks by the same invader. This adaptation step is followed by the expression phase, in which the CRISPR locus is transcribed into the precursor of CRISPR RNA (crRNA), multiunit pre-crRNA, which subsequently cleaves into the mature crRNA. Next, at the interference phase, the crRNA guides Cas nuclease to pinpoint and cleave the invader DNA or in some cases summons other nucleases to get involved. This process is accomplished by coupling of the spacer at $3^{\prime}$ end of crRNA with its complementary sequence on the foreign invader DNA. Of note, Presence of a short motif ( $2-5 \mathrm{bp}$ ) adjacent to crRNA target on the alien DNA (protospacer), called protospacer adjacent motif (PAM), would assure the tight binding of the crRNA-Cas complex in most types of CRISPR systems $[38,39]$. Interestingly, targeting invaders in type III and some subtypes of other CRISPR-Cas systems occurs through a PAM-independent procedure [40, 41]. Type III CRISPR targets ssDNA and RNA unspecifically and is completely ineffective in action with dsDNA [42]. Moreover, PAM absence restricts viral escape, which occurs in response to single-nucleotide mutation, and eliminates the need for incorporation of multiple spacers to ensure thorough immunity [43].

The most investigated type of CRISPR is type II (belonging to class 2), in which a single multidomain DNA endonuclease from Streptococcus pyogenes, namely Cas9, plays the pivotal role. Of note, Cas9 is solely analogous to the crRNA-Cas complex of class 1 CRISPR family [44]. In the type II CRISPR systems, cleavage of pre-crRNA into mature crRNA is achieved through the RNase III-catalyzed annealing of pre-crRNA with trans-activating crRNA (tracrRNA) encoded by type II CRISPR, leading to the formation of tracrRNA-crRNA [45]. This complex, accoutered with a 20-nt probe at its $5^{\prime}$ end, search for its complement sequence on the foreign DNA that possessing a PAM at its $3^{\prime}$ end. Afterwards, Cas binds to PAM through its PAM-interacting domain. Finally, unwinding and cleavage of target and non-target strands are handled by the $\mathrm{HNH}$ and RuvC nuclease domains of Cas9 [46].

Due to the straightforward architecture of type II in comparison to other types of CRISPR, its application has been widely expanded from prokaryotes' auto-immunity to the generation of site-specific double-strand break (DSB) at any desirable targets, both in vitro and in vivo. Moreover, chimeric single guide RNA (sgRNA) has been developed as an alternative guidance instead of both crRNA and tracRNA, which makes type II CRISPR-Cas system more simple and applicable [47].

Introduction of the blunt-ended DSB is followed by activation of repairing process, the error-prone nonhomologous end joining (NHEJ) and/or the homologydirected (HDR) pathway. Depending on the presence or absence of a repairing template, HDR or NHEJ mechanism would be followed, respectively (Fig. 2). Lack of repairing template results in the activation of NHEJ pathway in which random insertions and deletions (indels), as well as substitutions at the cleavage site cause flaws in target's function or even entirely suppress it. On the other hand, template-dependent 
Table 1 | CRISPR Classes, types, subtypes, and their original species

\begin{tabular}{|c|c|c|c|c|}
\hline Reference & Species & Subtype & Type & Class \\
\hline \multirow[t]{7}{*}{ [32] } & $\begin{array}{l}\text { Archaeoglobus fulgidus } \\
\text { AF1859, AF1870-AF1879 }\end{array}$ & I-A & I & 1 \\
\hline & $\begin{array}{l}\text { Clostridium Kluyveri } \\
\text { CKL_2758-CKL_2751 }\end{array}$ & I-B & & \\
\hline & $\begin{array}{l}\text { Bacillus halodurans } \\
\mathrm{BH} 0336-\mathrm{BH} 0342\end{array}$ & I-C & & \\
\hline & $\begin{array}{l}\text { Geobacter sulfurreducens } \\
\text { GSU0051-GSU0054, GSU0057-GSU0058 }\end{array}$ & $\mathrm{I} U$ & & \\
\hline & $\begin{array}{l}\text { Cyanothecesp. } 8802 \\
\text { Cyan8802_0527Cyan8802_052 }\end{array}$ & I-D & & \\
\hline & $\begin{array}{l}\text { Escherichia colik12 } \\
\text { ygcB-ygbF }\end{array}$ & I-E & & \\
\hline & $\begin{array}{l}\text { Yersinia pseudotuberculosis } \\
\text { YPK_1644-YPK_1649 }\end{array}$ & I-F & & \\
\hline \multirow[t]{8}{*}{ [34] } & $\begin{array}{l}\text { Shewanella putrefaciens CN-32 } \\
\text { Sputcn32_1819-Sputcn32_1823 }\end{array}$ & I-F (variant) & & \\
\hline & $\begin{array}{l}\text { Thioalkalivibrio sp. K90mix } \\
\text { TK90_2699-TK90_2703 }\end{array}$ & IV & IV & \\
\hline & $\begin{array}{l}\text { Rhodococcus jostii RHA1 } \\
\text { RHA1_ro10069-RHA1_ro10072 }\end{array}$ & IV (variant) & & \\
\hline & $\begin{array}{l}\text { Staphylococcus epidermidis } \\
\text { SERP2463-SERP2455 }\end{array}$ & III-A & III & \\
\hline & $\begin{array}{l}\text { Synechocystis sp. } 6803 \\
\text { sll7067-s\|l17063 }\end{array}$ & $\|||-D$ & & \\
\hline & $\begin{array}{l}\text { Methanothermobacter thermautotrophicus } \\
\text { MTH328-MTH323 }\end{array}$ & $\| I I-C$ & & \\
\hline & $\begin{array}{l}\text { Pyrococcus furiosus } \\
\text { PF1131-PF1124 }\end{array}$ & $\| I I-B$ & & \\
\hline & $\begin{array}{l}\text { Marinomonas mediterranea MMB_1 } \\
\text { Marme_0668-Marme_0677 }\end{array}$ & III-B (variant) & & \\
\hline \multirow[t]{3}{*}{ [35] } & $\begin{array}{l}\text { Legionella pneumophila str. Paris } \\
\text { Ipp0160-Ipp0163 }\end{array}$ & $\|-B$ & $\|$ & 2 \\
\hline & $\begin{array}{l}\text { Streptococcus thermophilus } \\
\text { str0657-str0660 }\end{array}$ & $\|-A$ & & \\
\hline & $\begin{array}{l}\text { Neisseria lactamica 020-06 } \\
\text { NLA_17660-NLA_17680 }\end{array}$ & $\|-C$ & & \\
\hline [34] & $\begin{array}{l}\text { Micrarchaeum acidiphilum ARMAN-1 } \\
\text { BK997_03320-BK997_03335 }\end{array}$ & II-C (variant) & & \\
\hline \multirow[t]{9}{*}{ [37] } & uncategorized & $V-F^{b}$ & V & \\
\hline & uncategorized & $V-F^{a}$ & & \\
\hline & $\begin{array}{l}\text { Bacillus thuringiensis HD-771 } \\
\text { BTG_31928 }\end{array}$ & V-U3 & & \\
\hline & $\begin{array}{l}\text { Rothia dentocariosa M567 } \\
\text { HMPREF0734_01291 }\end{array}$ & V-U4 & & \\
\hline & $\begin{array}{l}\text { Cyanothecesp. PCC } 8801 \\
\text { PCC8801_4127 }\end{array}$ & V-U2 & & \\
\hline & uncategorized & $\mathrm{V}-\mathrm{F}^{\mathrm{c}}$ & & \\
\hline & $\begin{array}{l}\text { Gordonia otitidis } \\
\text { GOOTI_RS19525 }\end{array}$ & V-U1 & & \\
\hline & uncategorized & $V-G$ & & \\
\hline & $\begin{array}{l}\text { Oleiphilus sp. } \\
\text { A3715_16885-A3715_16890 }\end{array}$ & $\mathrm{V}-\mathrm{C}$ & & \\
\hline
\end{tabular}


Table 1 (continued)

\begin{tabular}{|c|c|c|c|c|}
\hline Reference & Species & Subtype & Type & Class \\
\hline & $\begin{array}{l}\text { Bacterium CG09_39_24 } \\
\text { BK003_02070-BK003_02075 }\end{array}$ & V-D & & \\
\hline & $\begin{array}{l}\text { Francisella cf. novicida Fx1 } \\
\text { FNFX1_1431-FNFX1_1428 }\end{array}$ & V-A & & \\
\hline & $\begin{array}{l}\text { Deltaproteobacteria bacterium } \\
\text { A2Z89_08250-A2Z89_08265 }\end{array}$ & V-E & & \\
\hline & $\begin{array}{l}\text { Anabaena variabilis } \\
\text { Ava_2196 }\end{array}$ & V-U5 & & \\
\hline & $\begin{array}{l}\text { Alicyclobacillus acidoterrestris } \\
\text { N007_06525-N007_06535 }\end{array}$ & V-B & & \\
\hline & uncategorized & V-I & & \\
\hline & uncategorized & $\mathrm{V}-\mathrm{H}$ & & \\
\hline$[33,34]$ & $\begin{array}{l}\text { Leptotrichia shahii } \\
\text { B031_RS0110445 }\end{array}$ & $\mathrm{VI}-\mathrm{A}$ & $\mathrm{Vl}$ & \\
\hline \multirow[t]{2}{*}{ [36] } & $\begin{array}{l}\text { Eubacterium siraeum } \\
\text { DSM_15702 }\end{array}$ & VI-D1 & & \\
\hline & $\begin{array}{l}\text { Ruminococcus sp. } \\
\text { N15.MGS-57 }\end{array}$ & VI-D2 & & \\
\hline \multirow[t]{3}{*}{ [34] } & $\begin{array}{l}\text { Fusobacterium prefoetens } \\
\text { T364_RS0105110 }\end{array}$ & $\mathrm{VI}-\mathrm{C}$ & & \\
\hline & $\begin{array}{l}\text { Prevotella buccae } \\
\text { HMPREF6485_RS00335-HMPREF6485_RS00340 }\end{array}$ & VI-B1 & & \\
\hline & $\begin{array}{l}\text { Bergeyella zoohelcum } \\
\text { HMPREF9699_02005-HMPREF9699_02006 }\end{array}$ & VI-B2 & & \\
\hline
\end{tabular}

error-free HDR route repairs the cleaved DNA target through the introduction of high precision site-specific mutation, deletion, or/and insertion by comparing the target with a template that provides the desirable modified sequence among the flanked complement nucleotides [48].

By comparison with conventional nuclease-dependent gene-editing techniques, zinc finger nuclease and transcription activator-like effector nuclease, the superiority of CRISPR-Cas nuclease method arises from its straightforward design, as well as its high efficiency and cost-effectiveness. Unlike ZFN and TALEN that their target recognition is in demand of laborious protein design and synthesis for each target, CRISPR machinery is activated by guidance of a single RNA, sgRNA. Therefore, along with noticeable reduction in the time of design and construction, RNA leadership results in feasibility of CRISPR for multi-targeting, widespread genome manipulation or screening, and adoption in different biological contexts $[49,50]$.

\section{CRISPR applications, from fundamental studies to clinical trials}

CRISPR is widely used for many purposes; all are defined based on robust ability of CRISPR in gene editing. This technology not only has already found its way into molecular biology and genetic studies but also has penetrated among medical and pharmaceutical investigations [39]. Simplicity in design and feasibility in employment have paved the way for CRISPR to be exploited in diagnosis and modification of disorders at the level of nucleic acids. Moreover, CRISPR can be used at both genomic and epigenomic levels, for instance, live-cell chromatin imaging, gene expression control, nucleic acid detection, and epigenome editing [51]. In addition to host genome manipulation, CRISPR has been developed to combat viral infections and their subsequent maladies. Several pathogenic viruses, including hepatitis B virus, human papilloma virus (HPV), herpes virus, and human immunodeficiency virus type I have shown promising results in action with the CRISPR system and also some of these 


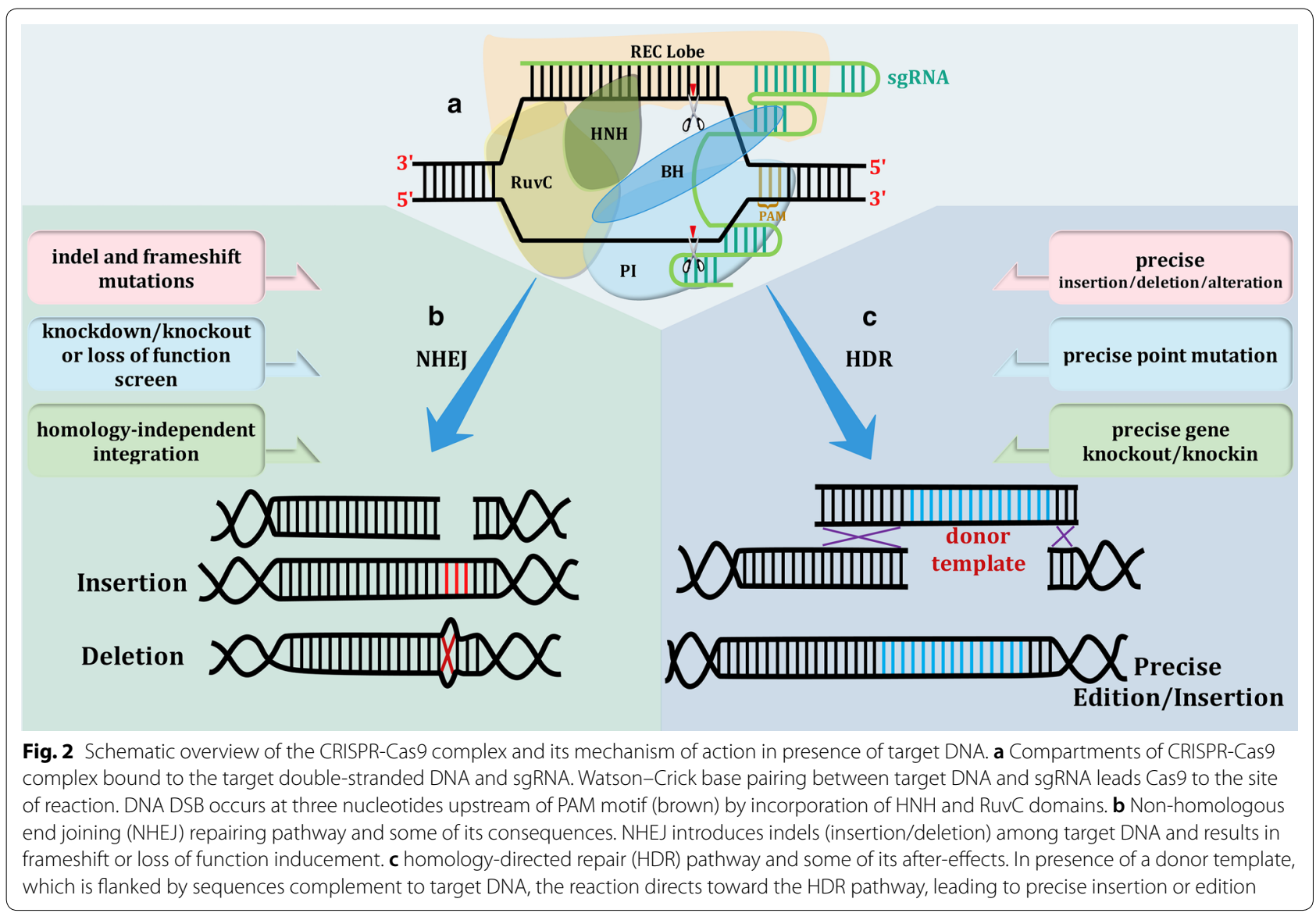

CRISPR-based treatments have entered into the clinical trials [52-56]. For instance, Zhu et al. introduced a safe method to target E7 in HPV-induced cervical cancer cells in vaginal context using poly $ß$-amino esterbased nanoparticles for delivery of CRISPR modules into xenograft tumor models, resulted in the knockout of E7 and thereby suppression of tumor progression [57]. Moreover, among all CRISPR-based therapeutic advancements, the utmost consideration has been given to the treatment of cancers. In addition, CRISPR is used to discover novel targets for further cancer therapy trials, by which anticancer drug targets and drug-resistant genes would be identified [6]. Furthermore, pinpointing the non-coding genome of cancer to complete the biological map of cancer along with the construction of organoid cancer models for in vitro investigations are the other preclinical applications of CRISPR in cancer area [58-60].

Besides, utilization of CRISPR has found many advocates among biomedical scientists. In addition to the genome and epigenome editing, manipulation of oncolytic viruses and modification of autologous tumorspecific T-cells by means of CRISPR-Cas system have currently been developed [61, 62].

Oncolytic virotherapy is another type of immunotherapy that employs oncolytic viruses for therapeutic purposes and can be used for treatment of a broad range of tumors [63]. As an example for the application of CRISPR in oncolytic virotherapy, CRISPR-Cas9 has been used to construct IL-15-expressing herpes simplex virus II, which showed potential in increasing the anti-tumor activity of T-cells and suppressing tumor growth in colon and gastric cancer models [64]. Moreover, CRISPR can be used in cancer vaccine studies to provide optimal environment for vaccine induction of enhanced immune responses against malignant cells. A very recent study has shown that CRISPR-mediated ablation of tumor cells' CD47 highly increased the whole tumor cells vaccine-induced immunity in hematopoietic and solid tumor models 
[65]. Today, many CRISPR-Cas9-mediated clinical trials for treatment of cancers including relapsed or refractory leukemia and lymphoma (NCT03398967 and NCT03166878), Acute Lymphoblastic Leukemia/Lymphoma and non-Hodgkin Lymphoma (NCT03690011), relapsed or refractory B-cell malignancies (NCT04035434), relapsed or refractory multiple myeloma (NCT04244656), non-small cell lung cancer (NCT02793856), mesothelin-positive solid multiple tumors (NCT03545815 and NCT03747965), and EBV-associated malignancies (NCT03044743) are under evaluation [66].

\section{CRISPR-Cas challenges and possible solutions}

Regardless of privileges associated with CRISPR-Cas system, some malfunctions of this technology and ethical concerns must meticulously be taken into account before entering the clinical stage [8].

Concerning the necessity for precise on-target activity of CRISPR-Cas, some studies have revealed that wildtype spCas9 is not potential to meet this requirement perfectly. to address this deficiency, development of some spCas9 mutants and its engineered homologs have led to the introduction of novel nucleases such as spCas9n, FokI-dCas9, and spCas9-HF1, which have shown improved efficacy in target specification compared to wtsp-Cas9 [67-69]. Moreover, a recent study demonstrated that adding a hairpin sequence to $5^{\prime}$ end of sgRNA highly increased the accuracy of the CRISPR editing outcome [70]. Regarding prediction of the precision of CRISPR editing, Chakrabarti et al. showed that depending on the upstream sequence of PAM, the characteristics of CRISPR is predictable to some extent, allowing researchers to increase the CRISPR accuracy by following some simple rules in the design of sgRNA [71].

Another concern related to CRISPR is the ratio of HDR to NHEJ, which directly affects the efficiency of in vivo gene editing. As previously mentioned, the NHEJ repairing mechanism results in the emergence of indels among target sequence. Many trials have been conducted to enhance the portion of HDR following DSB generation. As HDR mechanism is majorly limited to $S$ and G2 phases of cell cycle and therefore is dominated by the NHEJ pathway, many approaches including incorporation of single-stranded DNA donors, NHEJ suppressor molecules, and HDR enhancer molecules can be applied to increase the HDR ratio and thereby to improve the precision of CRISPR-Cas genome editing [72]. Moreover, postponement of initial Cas9 expression until S or G2 phases increases HDR:NHEJ ratio [73].

One of the most important problems immediately related to any gene therapy or gene drive methods is delivery. Many delivery tools have been developed, each one has its own advantageous and disadvantageous [74]. Generally, delivery methods by which CRISPR function has been assessed are categorized as physical, virally driven and non-viral vector methods. CRISPR machinery at the DNA level is delivered through viral vectors when long term activity be in demand. This method has the potential of high penetration into the target cells, and of being under tight control of an expression promoter that uses transcriptional machinery of host cells. Related to the type of virus, some points should be considered in order to prevent undesirable outcomes. Adeno-associated viruses (AAVs) are able to carry just about 4.5-5 kbp per particle, whereas the size of just spCas9 plus sgRNA is about $4.2 \mathrm{Kbp}$. Moreover, while lentiviruses and adenoviruses are benefiting from larger capacity than AAVs, the possibility of their undesired integration into the host genome as well as induction of strong immune responses are the major drawbacks of these two delivery tools [75, 76]. On the other hand, physical delivery techniques such as microinjection, electroporation, and hydrodynamic delivery are needless of any intermediate medium for delivery and activation, however, in vivo studies have disclosed their low efficiency to carry DNA particles to the target cells [77]. Among non-viral delivery methods, lipid nanoparticles have shown long-lasting stability and immune system compatibility. Other later developed non-viral delivery systems assayed at CRISPR gene-editing studies contain lipoplexes and polyplexes, cell-penetrating peptides, DNA nanoclew, induced transduction by osmocytosis and propanebetaine and gold nanoparticles $[76,78-80]$.

There are some other CRISPR-related concerns such as runaway immune responses and spatiotemporal malfunctions, which result in off-targeting and the decrease of productivity, which have found solutions like development of engineered or split Cas enzymes in order to have more control on in vivo activity of CRISPR-Cas system [81].

What must be considered over and above all mentioned challenges are ethical points. The tremendous need for the development of more effective and tolerable therapeutic methods to combat with ever-increasing malignancies should not lead to indiscriminate employment of those techniques before answering to all ethical questions created during initial trials, otherwise, it would immediately backfire $[82,83]$. Induction of tumor suppressive protein P53 impairment, and human somatic tissues or germline cells editing, whether intentional or unintentional, are among the ethical debates aroused around CRISPR technology, which are enough to elucidate the importance of the subject $[84,85]$. Additionally, some irresponsible deployment of CRISPR like the birth of CRISPR gene-manipulated twins in China should 
be prevented before the same fate as vaccines befalls CRISPR and stops it from its potential development [8, 86].

\section{The deluxe zone of cancer therapy, where CRISPR meets immunotherapy}

In order to push the autologous T-cells to their limits and beyond, engineered TCR and recombinant CAR T-cells have been developed. To enhance the function and customize the properties of T-cells according to the specific tumor type, original T-cells must be modified by means of a gene-editing tool before further procedures (Fig. 1a). It is the place where CRISPR gene-editing technology overlaps with progressive cancer immunotherapy [87].

\section{Applications of CRISPR in construction of recombinant TCR and CAR T-cells}

Embryonic T-cells, primary materials for construction of engineered T-cells, comprise native TCR complex that presents its own antigen specificity, which may interfere with both TCR and CAR T-cell therapies [88]. The potential of endogenous TCR to compete with recombinant transgenic therapeutic TCR in surface expression along with the likelihood of mixed TCR dimers formation (endogenous $\alpha$ with recombinant $\beta$ and vice versa) may result in poor expression of desired TCR among four possible combinations [89], and provocation of graft versus host disease (GVHD)-like syndrome [90]. Furthermore, in the context of universal T-cells, particularly CAR T-cells, the total number of expressed endogenous TCR heterodimers (either $\alpha \beta$-TCR or $\gamma \delta$-TCR) on the surface of physiological T-cells may be enough to provoke GVHD [91]. To avoid these common problems, many approaches have been investigated, among which the employment of gene-editing tools (ZFN, TALEN, and CRISPR) to knock out, knock down or modify endogenous TCR is the principal technique [92, 93]. Assessment of endogenous TCR manipulation by incorporation of three distinct nuclease-based gene-editing tools by Osborn et al. revealed that the CRISPR-Cas9 complex is able to disrupt the TRAC locus of TCR- $\alpha$ chain efficiently without any significant off-target activity or cytotoxicity. Subsequently, these CRISPR-mediated TRAC-knockout T-cells were employed to generate efficient CD19 CAR T-cells with promising results [94]. In another study, Legut et al. showed that CRISPR-mediated knockout of the endogenous TCR- $\beta$ chain is enough to enhance the expression level of either $\alpha \beta$ or $\gamma \delta$ recombinant TCR heterodimers. This observation can be explained by the low tendency toward formation of dimer between intact $\alpha$ chain of endogenous TCR with $\beta$ chain of engineered TCR in $\alpha \beta-T C R$ models and also incapability of cross-dimerization between $\alpha \beta$ and $\gamma \delta$ chains in $\gamma \delta$-TCR constructs [62]. Recently, CRISPR-driven knockout of both TRAC and TRBC, to disrupt exogenous $\alpha$ and $\beta$ chains, respectively, for construction of transgenic TCR T-cell was evaluated. This double knockout led to the enhancement of both expression and function of recombinant TCR T-cells and hence increased their potential in antigen-sensing and control of tumor growth in multiple myeloma models compared to homologous single-locus(TRAC or TRBC)-depleted TCR T-cells [95].

As CAR T-cells act particularly against tumor surface antigens and are independent of host genetics [96], they are one of the best candidates to construct universal off-the-shelf immunotherapeutic agents for rapid and ready-to-use clinical applications [97]. In addition to the previously described necessity to knock out the endogenous TCR, human leukocyte antigen (HLA) expression on the surface of universal CAR T-cells should be silenced, otherwise, the immune system would immediately reject allogeneic T-cells [98]. Furthermore, immune checkpoint blockade of inhibitory receptors (PD-1, Tim3, CTLA-4, LAG-3, DGK, FAS, etc.) postpones CAR T-cells exhaustion and reinforces them for clinical trials [99]. Both HLA knockout and immunosuppressive pathways blockade can be achieved by means of CRISPR without any detrimental immunological side-effects as observed during employment of blocking antibodies (Fig. 3a, b) [100, 101].

Ren et al. are the pioneers of harnessing CRISPR unique ability in hitting multiple targets at once to construct allogeneic universal CAR T-cells. First, they disclosed that fueling CRISPR machinery with six distinct gRNAs through electroporation to target TRAC, TRBC, B2 M (betta-2 Microglobulin, a subunit of HLA-I), and $\mathrm{PD}-1$ results in the generation of allogenic universal CAR T-cells that are immune from stimulation of GVHD [102]. Inspired by their first innovative design, they tried adding FAS blockade gRNA to their recipe to exploit more from the CRISPR power [103]. FAS (APO-1 or CD95) receptor is expressed on extracted T-cells and its interaction with apoptosis-inducing ligand FASL, present within most human tumor microenvironments, might lead to the exhaustion of CAR T-cells and decrease in their anti-tumor function [104]. The FAS ${ }^{-}$CD19 CAR T-cells, generated by simultaneous triple targeting of exogenous TCR, HLA-I, and FAS receptor in presence of eSPCas9 (the high fidelity version of Cas9) showed promising results in both in vitro and in vivo assays. However, when the number of CRISPR targets increased to include PD-1 and CTLA4 checkpoints, the yield of disruption dropped. This decline was due to the congestion of different gRNAs to compete for the use of Cas enzyme and also the limitations associated with the lentiviral vector 
delivery method [103]. In another study on lung cancer models, $\$ 2 \mathrm{~m}$ blockade by applying CRISPR-Cas resulted in resistance to immune checkpoint inhibitors (ICIs), especially PD-1, proving the effect of HLA-I suppression on the tumor responses to ICIs [105]. Rupp et al. reported that CRISPR-Cas9-mediated Pdcd1 (PD-1) suppression in anti-CD19 CAR T-cells augments their effectiveness in destroying cancer cells in vitro using Human CD19 $\mathrm{K} 62^{+}$myelogenous leukemia cell line as a model, and also improves PD- $1^{+}$tumor clearance in mouse xenograft models [106]. Interestingly, utilizing CRISPR to turn off the PD-L1 gene in two tumor models, MC38 and CT26, revealed that in addition to cancerous tissues, infiltrating immune cells express PD-L1 in tumor-bearing mice models [107]. The result points out the necessity of multidimensional view for designing therapeutic tools for cancer immunotherapy purposes.

Regardless of Ren et al. studies that aimed at targeting multiple sites using distinct gRNAs for each target in one-shot CRISPR treatment, Eyquem et al. introduced a novel method to create TCR ${ }^{-}$CD19 CAR T-cells through single target manipulation. This study demonstrated that CRISPR-mediated insertion of the CD-19 CAR into the exon 1 of the TCR $\alpha$ chain (the TRAC locus) not only

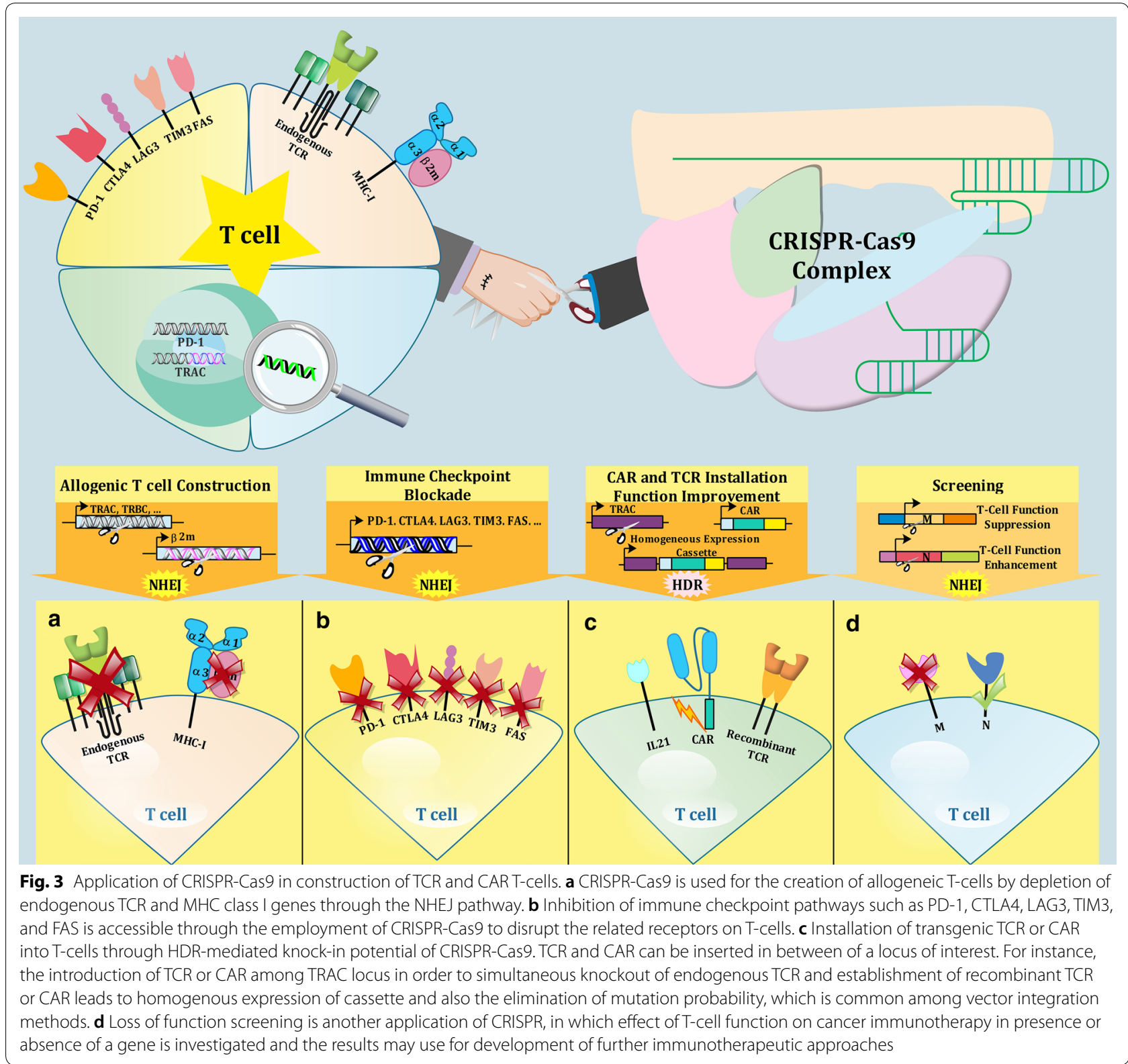


establishes the CAR machinery properly but also knocks out the exogenous TCR simultaneously (Fig. 3c). Moreover, using this novel construct, namely TRAC-CAR, in the treatment of precursor-B acute lymphoblastic leukemia NALM-6 mice models showed a significant decrease in expression of three important exhaustive markers (PD-1, LAG3, and TIM3) from 50\% in routine CARs to below $2 \%$ in this redesigned version [108]. In order to minimize the heterogeneity among recombinant $\mathrm{T}$-cells, Georgiadis et al. innovated a procedure through which Pol III- and TRAC-targeting sgRNAs were assembled with CD19 CAR into a self-inactivating lentiviral vector. Simultaneous expression of this recombinant vector with electroporation of Cas9 mRNA led to a homogenous response of Terminal-TRAC CAR T-cells against leukemia in Human xenograft tumor models [109]. Unlike the previously mentioned studies that employed electroporation for CRISPR-mediated ablation of troublesome receptors of $\mathrm{T}$ cells, $\mathrm{Hu}$ et al. evaluated nucleofection as a simpler and more robust alternative technique to disrupt PD-1 receptor and PiggyBac transposon in CD133 CAR T-cells. This method yielded more than 90 percent disruption of PD-1 and the recombinant CARs showed better anti-glioma responses both in vitro and in mice models compared to conventional CD133 CAR T-cell immunotherapy [110].

To address the concern associated with isolation and sufficient expansion of CRISPR-modified T-cells, Shao et al. [111] indicated that due to notable cytotoxic effector properties, engineered cells for costimulatory enhancement [112] in combination with Interleukin 21 provided a rich media for PD-1-disrupted (by CRISPR) cytotoxic $\mathrm{T}$ lymphocytes culture and thereby resulted in improvement of immune responses against AGS-EBV cell line in vitro [111].

Identification of cancer cells by CARs is limited to the recognition of membrane antigens, which contain only below one percent of all expressed proteins. This limitation create a barrier to the vast deployment of CAR T-cells in cancer immunotherapy [113]. The primary concern related to this deficiency is the probability of the presence of the same target antigen on the surface of healthy cells, which may give rise to the so called "on-target, off-tumor" phenomenon [114]. For instance, both healthy and cancerous myeloid cells express CD33 and therefore traditional CD33 CAR T-cell therapy of acute myeloid leukemia (AML), which is in phase I and I/II clinical trials, would disrupt non-cancerous normal cells too $[115,116]$. Whereas tumor-specific antigen has not been identified for many tumors like some types of AML [117], and in order to prevent previously described on-target, off-tumor occurrence, two studies have demonstrated that baring the hematopoietic stem and progenitor cells from CD33 using CRISPR-Cas9 and successful transplantation of these CD33-knockout cells resulted in the safe and fully on-target, on-tumor activity of CD33-targeted CAR T-cells against AML [118, 119]. On the other hand, CD7 is a specific potential target for AML cells, but is observed in about $30 \%$ of all patients. Using CRISPR to disrupt interfering CD7 gene in CD7 CAR T-cells and to create CD7-knockout KG-1a cell line as control, Gomes-Silva et al. succeeded in the development of CD7 CAR against AML [120]. Recently, CAR T-cells targeting CD79b receptor, alone or combined with CD19, have been developed against B-cell lymphomas. And evaluation of these novel CARs in vitro and in xenograft models using CRISPR-mediated CD19- MCL cell lines showed favorable results in avoiding CD19 antigen escape, reported in previous CD19 CAR T-cell therapies of B-cell lymphomas [121].

In order to broaden CAR applications from the treatment of hematological malignancies to solid tumors, utilization of appropriate antigen receptors and suppression of some limiting immune checkpoints are integral [122]. In this context, Hu et al. constructed PD-1 ${ }^{-}$Meso (Mesothelin) CAR T-cells using CRISPR-Cas9 to apply against TNBC, one of the most malign types of breast cancer resistant to hormonal therapy or therapies dealing with HER2 protein receptors. They observed that CRISPRmediated PD-1-disrupted Meso CARs perform superior to untreated control Meso CARs [123]. Moreover, TIL therapy of $\mathrm{EBV}^{+}$gastric cancer using CRISPR to generate $\mathrm{PD}-\mathrm{1}^{-} \mathrm{T}$-cells opened a promising window for the treatment of chemotherapy-resistant type of gastric cancer [124]. Using the same approach, Guo et al. indicated that Hepatocellular Carcinoma cells are totally incapable of tolerating CRISPR-mediated PD-1' GPC3 CAR T-cell therapy [125]. Very recently and for the first time in solid tumors, study on a recombinant anti-EGFRvIII CAR T-cell through co-disruption of TRAC, $32 \mathrm{M}$ and PDCD1 genes by means of CRISPR-Cas9 showed higher anti-glioma activities compared to previous anti-EGFRvIII CAR T-cell therapies [126]. Similarly, and this time CRISPRCas9-based knockout of PD-1 resulted in efficient antiEGFRvIII CAR T-cells against glioblastoma, providing promising results for future clinical trials [127]. As previously mentioned, CAR T-cell exhaustion due to exposure to immunosuppressive microenvironment of tumor cells is an important drawback of deploying CAR T-cells against solid tumors. In this context, CRISPR-Cas9mediated disruption of TGF- $\beta$ receptor II gave rise to the production of highly efficient CAR T-cells with resistance to exhaustion, when used against solid tumors whose microenvironment is rich in TGF- $\beta$. These modified CAR T-cells also induced a decline in the TGF- $\beta$-induced conversion of regulatory $\mathrm{T}$ (Treg) cells [128]. In addition to 
CAR T-cells, using CRISPR-modified tumor-specific effector memory T-cells can be considered as an appropriate alternative for immunotherapy of solid tumors [129].

\section{Assisting applications of CRISPR in development of cancer immunotherapy}

CRISPR plays a key role in preclinical studies of modern cancer immunotherapy. In this context, Qin et al. used CRISPR to create $\mathrm{CD}^{-} 9^{-}$or CD22- B-acute lymphoblastic leukemia NALM6 cell line in order to control the efficiency of their double-barreled CD19 CD22 CAR. In spite of reported challenges in the establishment of both receptors, the results of that study are promising in development and optimization of novel multi-targeting CARs, which not only reduce the possibility of antigen escape but also increase the efficacy of CAR T-cell therapy [130].

Resistance to immune checkpoint blocking therapy is a prevalent phenomenon observed in many tumors, in particular, "cold" tumors, a term attributed to tumors whose microenvironment is not appropriate for infiltration of tumor-specific T-cells [131]. In this regard, Tu et al. developed a weak-acidity-responsive nanoparticle for efficient delivery of cyclin-dependent kinase 5-targeting CRISPR-Cas9 (to suppress PD-L1 expression on tumor cells [132]) and paclitaxel (to trigger anti-tumor immune responses) to the tumor site, and thereby succeeded to exchange tumor microenvironment from "cold" to "hot" and to inhibit tumor growth in melanoma and colorectal cancer mice models [133].

\section{CRISPR-mediated screening for potential immunotherapeutic targets}

CRISPR has also been used for genome screening to determine regulatory elements that play vital roles in innate and adaptive immune pathways associated with cancer, which may be applicable for cancer immunotherapy (Fig. 3d) [134, 135]. Shifrut et al. conducted pooled screening for loss-of-function T-cells through lentiviral-based sgRNA delivery vectors and Cas9 electroporation in order to find key regulatory elements of TCR response. That study revealed that the knockout of some T-cells regulatory proteins such as SOCS1, TCEB2, RASA2 and CBLB improves both proliferation and anticancer capability of modified T-cells [136]. To explain how three subunits of PBAF (Polybromo-associated BRG1-associated factor) chromatin-remodeling complex, including ARID2, PBRM1 and BRD7 regulate T-cell effectiveness against tumor cells, Pan et al. used CRISPR to knock out each of those subunits separately in B16F10 cell line. Exposure of CRISPR gRNA library transduced B16F10 ${ }^{\text {Cas9 }}$ cells to cytotoxic T-cells indicated an enhancement in T-cell-mediated cytotoxic effect on impaired PBAF cells and in secretion of IFN- $\gamma$-inducing chemokines such as $\mathrm{Cxcl} 9$ and Cxcl10, leading to augmented activity of T-cells and antitumor responses [137]. In a pooled CRISPR-Cas9 mutagenesis screening, it has been demonstrated that suppression of REGNASE-1 enhanced $\mathrm{CD}^{+}{ }^{+}$T-cells anti-tumor functions. Further analysis also determined BATF as the principal target of REGNASE-1 and introduced PTPN2 and SOCS1 as factors whose targeting by CRISPR improves the efficiency of REGNASE-1- CD8 ${ }^{+}$T-cells [138]. CRISPR screening has also clarified the impeding role of anti-silencing function 1A histone chaperone in anti-PD-1 immunotherapy of KRAS-mutant lung adenocarcinoma patients [139].

Interestingly, CRISPR-Cas9 genome screening has introduced major histocompatibility complex, class I-related (MR1) protein as a tumor-specific target for non-conventional TCR T-cells. The attractiveness of this discovery comes from the unvaried nature of MR1, due to its mandatory involvement in some microbial metabolism pathways, as well as MR1 expression on many cancer types cells but not healthy cells, which makes it a good candidate for ACT immunotherapy. Incorporation of MR1-recognizing TCR into patients-derived T-cells resulted in efficient destruction of melanoma cells by recombinant MR1 TCR T-cells [140].

Several CRISPR-mediated investigations have performed to determine key regulatory elements contributing to cancer immunotherapy and the results have revealed the role of granulocyte-macrophage colonystimulating factor in CD19 CAR T-cells administration [141], TNF- $\alpha$ autocrine level in performance of myeloid-derived suppressor cells [142], lysosome-associated membrane protein type $2 \mathrm{a}$ in regulation of tumor-associated macrophages [143], histone demethylase LSD1 in stimulation of anti-tumor responses [144], transcriptional co-activator with PDZ-binding motif in PD-L1 level [145], and Foxp $3^{+}$Treg cells in tumor advancement [146], to name a few.

In order to determine key pathways by which tumor cells restrict T-cells effector function, Kearney et al. performed a CRISPR-based genome screening and identified targets whose knockout resulted in resistance of malignant cells against T-cell attack. The findings of that study on $\mathrm{MC} 38^{\mathrm{Ova}}$ and $\mathrm{B} 16^{\text {Ova }}$ cells demonstrated that elimination of some genes from three primary pathways, including antigen presentation, IFN- $\gamma$ signaling, and TNF signaling leads to resistance of tumor cells to both $\mathrm{T}$ and NK cells both in vitro and in vivo [147]. Moreover, study on bone marrow T-cells, extracted from pediatric ALL patients, as a potential source of lymphocytes for TIL therapy, indicated the high levels of $\mathrm{TIM}^{+} \mathrm{CD}^{+}$ $\mathrm{T}$ cells, which highly increase the probability of ALL relapse. Further analysis by means of CRISPR showed a 
direct correlation between the level of TIM-3, thereby increased level of CD200, and malfunction of T-cells against leukemia cells [148]. Intriguingly, CRISPR-mediated permanent depletion of FOXP1 in diffuse large B-cell lymphoma cell line model, an R-CHOP resistance type of non-Hodgkin lymphoma, gave rise to upregulation of MHC Class II (I-Ab) on the cell surface and therefore increased the survival rate of tumor-bearing mice models [149]. In order to elucidate the possible combinatorial role of anti-cancer or other drugs in preventing resistance to CAR T-cell immunotherapy, i.e., immunomodulatory impacts of drugs on cytotoxic properties of effector T-cells, and to explore the mechanism of CAR T-cell cytotoxicity, a detailed in vitro loss-of-function screening by means of CRISPR has conducted recently. The results revealed that cancer genetics affects the output of CAR T-cell therapy and also introduced the key role of signaling by death receptors in cytotoxic mechanism of CAR T-cells [150].

\section{The semi-blindfold, first human clinical trial of CRISPR-assisted cancer immunotherapy}

The previously mentioned investigations were restricted to in vitro or non-human in vivo studies. First CRISPRmediated human cancer immunotherapy was conducted in 2016 by collaboration of three groups of experts, but after very limited preclinical evaluation. In that phase I human trial, the tumor antigen NY-ESO-1 was selected to construct recombinant TCR T-cells whose endogenous TCR and PD-1 genes were knocked out by CRISPR technology [151]. These NY-ESO-1-redirected CRISPR-edited T-cells (NYCE cells) were employed for the treatment of melanoma, synovial sarcoma and multiple myeloma with the participation of six patients for each cancer type [152]. Regardless of results, many ethical issues are attributed to this semi-blindfold administration of CRISPR-manipulated T-cells [153]. Detailed research on shortages of the NYCE cell employment revealed many hidden angles of this trial. Among the results, some including maladjustment of pre-clinical and clinical conditions, restriction of pre-clinical assessment to just one case, and lack of isolation procedure to generate a homogenous cell population, characterizing PD- ${ }^{-}$ $\mathrm{TCR}^{\mathrm{KO}-\alpha \beta}$ NY-ESO-1 T-cells, are more significant [152].

\section{Conclusion}

Cancer immunotherapy is based on stimulation of the immune system against malignant cells in order to destroy them without any notable harmful effect on non-cancerous healthy cells. Effective function of immune system is dependent on precise identification of tumor cells by immune modules and on presence of adequate innate and adaptive immune cells in the tumor microenvironment. Initial immunotherapy trials were based on using antibodies to inhibit the immune checkpoint pathways. Regardless of some advancements in treatment of a number of cancers, some limitations such as low capacity to control the procedure of immunotherapy, inadequate native T-cell in some tumors [10, 154], and side-effects of immune checkpoint blockade [155] pushed scientists to use novel gene-editing technologies to develop customized T-cells for more efficient immunotherapy. The contemporaneousness of modern cancer immunotherapy with gene-engineering techniques has opened doors to treatment of a wide range of cancers that were considered untreatable before then. Using CRISPR to simultaneously knock out endogenous TCR, MHC-I and many immune checkpoints to construct allogeneic universal T-cells (universal TCR and CAR T-cells) have enabled scientists to focus on advanced parts of cancer immunotherapy such as the development of receptors specialized for recognition of cancer-specific antigens, as well as minimizing side-effects and off-target activity of T-cells. Many challenges such as optimal dosage, homogeneity of T-cell population to generate controlled responses, antigen escape, selection of appropriate immunotherapy target, off-target off-tumor or on-target off-tumor activity of recombinant T-cells, immune-related adverse effects, and more importantly, human-health-related ethical concerns should be addressed before accepting the engineered T-cell cancer immunotherapy as a routine clinical cancer treatment method.

\section{Abbreviations}

TCR: T-cell receptor; CAR: Chimeric antigen receptor; ACT: Adoptive cell transfer; TILs: Tumor-infiltrating lymphocytes; CRISPR: Clustered regularly interspaced short palindromic repeats; ZFNs: Zinc finger nucleases; TALENs: Transcription activator-like effector nucleases; NK: Natural killer; PD-1: Programmed cell death 1; PD-L1: Programmed death-ligand 1; ALL: Acute lymphoid leukemia; crRNA: CRISPR RNA; PAM: Protospacer adjacent motif; tracrRNA: Trans-activating crRNA; DSB: Double-strand break; sgRNA: Single guide RNA; NHEJ: Nonhomologous end joining; HDR: Homology-directed; HPV: Human papilloma virus; AAVs: Adeno-associated viruses; GVHD: Graft versus host disease; HLA: Human leukocyte antigen; ß2M: Betta-2 Microglobulin; ICls: Immune checkpoint inhibitors; AML: Acute myeloid leukemia; Treg: Regulatory T; PBAF: Polybromo-associated BRG1-associated factor.

Acknowledgements

Not applicable.

Authors' contributions

S.M.M, E.T and A.G. drafted the study concepts and design; S.M.M, W.C.C and A.G. accomplished the literature research. All authors read and approved the final manuscript.

Funding

Not applicable.

Availability of data and materials Not applicable. 
Ethics approval and consent to participate

Not applicable.

\section{Consent for publication}

Not applicable.

\section{Competing interests}

The authors declare that they have no competing interests.

\begin{abstract}
Author details
1 Department of Chemistry, Sharif University of Technology, Tehran, Iran.

${ }^{2}$ Molecular Medicine Department, Biotechnology Research Center, Pasteur Institute of Iran, Tehran, Iran. ${ }^{3}$ Department of Clinical Oncology, Queen Elizabeth Hospital, Hong Kong, China. ${ }^{4}$ Department of Virology, Pasteur Institute of Iran, Tehran, P.O.Box: 1316943551, Iran.
\end{abstract}

Received: 23 June 2020 Accepted: 9 September 2020

Published online: 15 September 2020

\section{References}

1. Bray F, Ferlay J, Soerjomataram I, Siegel RL, Torre LA, Jemal A. Global cancer statistics 2018: GLOBOCAN estimates of incidence and mortality worldwide for 36 cancers in 185 countries. CA Cancer J Clin. 2018;68:394-424.

2. Sun L, Chen L, Li H. Checkpoint-modulating immunotherapies in tumor treatment: Targets, drugs, and mechanisms. Int Immunopharmacol Elsevier. 2019;67:160-75.

3. Keshavarz M, SolaymaniMohammadi F, Miri SM, Ghaemi A. Oncolytic paramyxoviruses-induced autophagy; a prudent weapon for cancer therapy. J Biomed Sci. 2019;26:48.

4. Maus MV, Fraietta JA, Levine BL, Kalos M, Zhao Y, June CH. Adoptive immunotherapy for cancer or viruses. Annu Rev Immunol. 2014:32:189-225.

5. Bommareddy PK, Shettigar M, Kaufman HL. Integrating oncolytic viruses in combination cancer immunotherapy. Nat Rev Immunol. 2018;18:1-16

6. Huang $\mathrm{CH}$, Lee KC, Doudna JA. Applications of CRISPR-Cas enzymes in cancer therapeutics and detection. Trends Cancer. 2018;4:499-512.

7. Manguso RT, Pope HW, Zimmer MD, Brown FD, Yates KB, Miller BC, et al. In vivo CRISPR screening identifies Ptpn2 as a cancer immunotherapy target. Nature Nature Publishing Group. 2017;547:413-8.

8. Benston S. Everything in moderation, even hype: learning from vaccine controversies to strike a balance with CRISPR. J Med Ethics. 2017:43:819-23.

9. McCarthy EF. The toxins of William B. Coley and the treatment of bone and soft-tissue sarcomas. lowa Orthop J. 2006. 26:154-8.

10. Rao S, Gharib K, Han A. Cancer Immunosurveillance by T Cells. Int Rev Cell Mol Biol. Elsevier Ltd; 2019. p. 149-73.

11. Yang J, Chen J, Wei J, Liu X, Cho WC. Immune checkpoint blockade as a potential therapeutic target in non-small cell lung cancer. Expert Opin Biol Ther. 2016;16:1209-23.

12. Cho WCS, Roukos DH. Trastuzumab emtansine for advanced HER2positive breast cancer and beyond: genome landscape-based targets. Expert Rev Anticancer Ther. 2013;13:5-8.

13. Tahamtan A, Ghaemi A, Gorji A, Kalhor HR, Sajadian A, Tabarraei A, et al. Antitumor effect of therapeutic HPV DNA vaccines with chitosan-based nanodelivery systems. J Biomed Sci. 2014;21:69.

14. Chow JCH, Man Cheung KM, Cho WCS. Atezolizumab in non-small cell lung cancer: the era of precision immuno-oncology. Ann Transl Med. 2017:5:265-265.

15. Bobanga I, Petrosiute A, Huang A. Chemokines as cancer vaccine adjuvants. Vaccines. 2013;1:444-62.

16. Moeini S, Saeidi M, Fotouhi F, Mondanizadeh M, Shirian S, Mohebi A, et al. Synergistic effect of programmed cell death protein 1 blockade and secondary lymphoid tissue chemokine in the induction of antitumor immunity by a therapeutic cancer vaccine. Arch Virol Springer Vienna. 2017;162:333-46.

17. Gableh F, Saeidi M, Hemati S, Hamdi K, Soleimanjahi H, Gorji A, et al. Combination of the toll like receptor agonist and a-Galactosylceramide as an efficient adjuvant for cancer vaccine. J Biomed Sci. Journal of Biomedical Science; 2016;23:16.

18. Usman WM, Pham TC, Kwok YY, Vu LT, Ma V, Peng B, et al. Efficient RNA drug delivery using red blood cell extracellular vesicles. Nat Commun. Springer US; 2018;9:2359.

19. Lizée G, Overwijk WW, Radvanyi L, Gao J, Sharma P, Hwu P. Harnessing the power of the immune system to target cancer. Annu Rev Med. 2013;64:71-90.

20. Sim GC, Chacon J, Haymaker C, Ritthipichai K, Singh M, Hwu P, et al. Tumor-infiltrating lymphocyte therapy for melanoma: rationale and issues for further clinical development. BioDrugs. 2014;28:421-37.

21. Spear TT, Nagato K, Nishimura MI. Strategies to genetically engineer T cells for cancer immunotherapy. Cancer Immunol Immunother. Springer Berlin Heidelberg; 2016;65:631-49.

22. Chmielewski M, Hombach AA, Abken H. Antigen-specific T-Cell Activation Independently of the MHC: chimeric antigen receptor-redirected T cells. Front Immunol. 2013;4:1-8.

23. Androulla MN, Lefkothea PC. CART-cell therapy: a new era in cancer immunotherapy. Curr Pharm Biotechnol. 2018;19:5-18.

24. Harris DT, Kranz DM. Adoptive T cell therapies: a comparison of T cell receptors and chimeric antigen receptors. Trends Pharmacol Sci Elsevier Ltd. 2016;37:220-30.

25. Lim WA, June $\mathrm{CH}$. The principles of engineering immune cells to treat cancer. Cell. 2017;168:724-40.

26. Chmielewski M, Hombach AA, Abken H. Of CARs and TRUCKs: chimeric antigen receptor (CAR) T cells engineered with an inducible cytokine to modulate the tumor stroma. Immunol Rev. 2014;257:83-90.

27. Kloss CC, Condomines M, Cartellieri M, Bachmann M, Sadelain M. Combinatorial antigen recognition with balanced signaling promotes selective tumor eradication by engineered T cells. Nat Biotechnol Nature Publishing Group. 2013;31:71-5.

28. Park JH, Geyer MB, Brentjens RJ. CD19-targeted CAR T-cell therapeutics for hematologic malignancies: interpreting clinical outcomes to date. Blood. 2016;127:3312-20

29. Castella M, Boronat A, Martín-Ibáñez R, Rodríguez V, Suñé G, Caballero M, et al. Development of a Novel Anti-CD19 Chimeric Antigen Receptor: A Paradigm for an Affordable CART Cell Production at Academic Institutions. Mol Ther - Methods Clin Dev. Elsevier Ltd.; 2019;12:134-44.

30. Guedan S, Ruella M, June CH. Emerging Cellular Therapies for Cancer. Annu Rev Immunol. 2019:37:annurev-immunol-042718-041407.

31. Westra ER, Dowling AJ, Broniewski JM, van Houte S. Evolution and ecology of CRISPR. Annu Rev Ecol Evol Syst. 2016;47:307-31.

32. Makarova KS, Wolf Yl, Alkhnbashi OS, Costa F, Shah SA, Saunders SJ, et al An updated evolutionary classification of CRISPR-Cas systems. Nat Rev Microbiol. 2015;13:722-36.

33. Shmakov S, Abudayyeh OO, Makarova KS, Wolf YI, Gootenberg JS, Semenova E, et al. Discovery and functional characterization of diverse class 2 CRISPR-Cas Systems. Mol Cell Elsevier Ltd. 2015;60:385-97.

34. Koonin EV, Makarova KS, Zhang F. Diversity, classification and evolution of CRISPR-Cas systems. Curr Opin Microbiol. Elsevier Ltd. 2017;37:67-78.

35. Shmakov S, Smargon A, Scott D, Cox D, Pyzocha N, Yan W, et al. Diversity and evolution of class 2 CRISPR-Cas systems. Nat Rev Microbiol Nature Publishing Group. 2017;15:169-82.

36. Yan WX, Chong S, Zhang H, Makarova KS, Koonin E V., Cheng DR, et al. Cas13d Is a Compact RNA-Targeting Type VI CRISPR Effector Positively Modulated by a WYL-Domain-Containing Accessory Protein. Mol Cell. Elsevier Inc.; 2018. 70:327-339.e5.

37. Yan WX, Hunnewell $P$, Alfonse LE, Carte JM, Keston-Smith E, Sothiselvam $\mathrm{S}$, et al. Functionally diverse type V CRISPR-Cas systems. Science (80-). 2019.363:88-91.

38. Khan S, Mahmood MS, Rahman SU, Zafar H, Habibullah S, Khan Z, et al. CRISPR/Cas9: the Jedi against the dark empire of diseases. J Biomed Sci. 2018. 25:29.

39. Hille F, Richter H, Wong SP, Bratovič M, Ressel S, Charpentier E. The biology of CRISPR-Cas: backward and forward. Cell. 2018;172:1239-59.

40. Kazlauskiene M, Tamulaitis G, Kostiuk G, Venclovas Č, Siksnys V. Spatiotemporal control of type III-A CRISPR-Cas immunity: coupling DNA degradation with the target RNA recognition. Mol Cell. 2016;62:295-306 
41. Harrington LB, Burstein D, Chen JS, Paez-Espino D, Ma E, Witte IP, et al. Programmed DNA destruction by miniature CRISPR-Cas 14 enzymes. Science (80-). 2018. 362:839-42.

42. Liu TY, lavarone AT, Doudna JA. RNA and DNA Targeting by a Reconstituted Thermus thermophilus Type III-A CRISPR-Cas System. Korolev S, editor. PLoS ONE. 2017. 12:e0170552.

43. Pyenson NC, Gayvert K, Varble A, Elemento O, Marraffini LA. Broad Targeting Specificity during Bacterial Type III CRISPR-Cas Immunity Constrains Viral Escape. Cell Host Microbe. Elsevier Inc: 2017. 22:343-353.e3.

44. Lier C, Baticle E, Horvath P, Haguenoer E, Valentin A-S, Glaser P, et al. Analysis of the type II-A CRISPR-Cas system of Streptococcus agalactiae reveals distinctive features according to genetic lineages. Front Genet. 2015:6:1-12.

45. Deltcheva E, Chylinski K, Sharma CM, Gonzales K, Chao Y, Pirzada ZA, et al. CRISPR RNA maturation by trans-encoded small RNA and host factor RNase III. Nature. 2011:471:602-7.

46. Edraki A, Mir A, Ibraheim R, Gainetdinov I, Yoon Y, Song C-Q, et al. A compact, high-accuracy Cas9 with a dinucleotide PAM for in vivo genome editing. Mol Cell. 2019;73(714-726):e4.

47. Bak RO, Gomez-Ospina N, Porteus MH. Gene editing on center stage. Trends Genet Elsevier Ltd. 2018;34:600-11.

48. Jasin M, Haber JE. The democratization of gene editing: Insights from site-specific cleavage and double-strand break repair. DNA Repair. 2016. 44:6-16.

49. Gutierrez-Guerrero A, Sanchez-Hernandez S, Galvani G, PinedoGomez J, Martin-Guerra R, Sanchez-Gilabert A, et al. Comparison of zinc finger nucleases versus CRISPR-specific nucleases for genome editing of the wiskott-aldrich syndrome locus. Hum Gene Ther. 2018;29:366-80.

50. Lee HB, Sundberg BN, Sigafoos AN, Clark KJ. Genome engineering with TALE and CRISPR systems in neuroscience. Front Genet. 2016;7:1-24.

51. Liu H, Wang L, Luo Y. Blossom of CRISPR technologies and applications in disease treatment. Synth Syst Biotechnol. 2018. 3:217-28.

52. Seeger C, Sohn JA. Targeting Hepatitis B Virus With CRISPR/Cas9. Mol Ther - Nucleic Acids. IOP Publishing; 2014. 3:e216.

53. Kennedy EM, Kornepati AVR, Goldstein M, Bogerd HP, Poling BC, Whisnant AW, et al. Inactivation of the human papillomavirus E6 or E7 gene in cervical carcinoma cells by using a bacterial CRISPR/Cas RNA-guided endonuclease. J Virol. 2014:88:11965-72

54. van Diemen FR, Kruse EM, Hooykaas MJG, Bruggeling CE, Schürch AC, van Ham PM, et al. CRISPR/Cas9-Mediated Genome Editing of Herpesviruses Limits Productive and Latent Infections. Nelson JA, editor. PLOS Pathog. 2016. 12:e1005701.

55. Kennedy EM, Cullen BR. Gene editing: a new tool for viral disease. Annu Rev Med. 2017:68:401-11.

56. Tsang H-F, Chan LW-C, Tong JC-H, Wong H-T, Lai CK-C, Au TC-C, et al. Implementation and new insights in molecular diagnostics for HIV infection. Expert Rev Mol Diagn. Taylor \& Francis. 2018. 18:433-41.

57. Zhu D, Shen H, Tan S, Hu Z, Wang L, Yu L, et al. Nanoparticles based on poly ( $\beta$-Amino Ester) and HPV16-Targeting CRISPR/shRNA as potential drugs for HPV16-related cervical malignancy. Mol Ther 2018:26:2443-55.

58. Fang Y, Fullwood MJ. Roles, Functions, and Mechanisms of Long Noncoding RNAs in Cancer. Genomics Proteomics Bioinformatics. Beijing Institute of Genomics, Chinese Academy of Sciences and Genetics Society of China. 2016. 14:42-54.

59. Drost J, van Boxtel R, Blokzijl F, Mizutani T, Sasaki N, Sasselli V, et al. Use of CRISPR-modified human stem cell organoids to study the origin of mutational signatures in cancer. Science (80-). 2017. 358:234-8.

60. Fujii M, Clevers H, Sato T. Modeling Human Digestive Diseases With CRISPR-Cas9-Modified Organoids. Gastroenterology. Elsevier, Inc; 2019. 156:562-76.

61. Yuan M, Webb E, Lemoine N, Wang Y. CRISPR-Cas9 as a powerful tool for efficient creation of oncolytic viruses. Viruses. 2016;8:72.

62. Legut M, Dolton G, Mian AA, Ottmann OG, Sewell AK. CRISPR-mediated TCR replacement generates superior anticancer transgenic $T$ cells. Blood. 2018:131:311-22

63. Keshavarz M, Ebrahimzadeh MS, Miri SM, Dianat-Moghadam H, Ghorbanhosseini SS, Mohebbi SR, et al. Oncolytic Newcastle disease virus delivered by Mesenchymal stem cells-engineered system enhances the therapeutic effects altering tumor microenvironment. Virol J. 2020. 17:64.

64. Cai L, Hu H, Duan H, Li Y, Zou Z, Luo K, et al. The construction of a new oncolytic herpes simplex virus expressing murine interleukin- 15 with gene-editing technology. J Med Virol. 2020. jmv.25691.

65. Li Y, Zhang M, Wang X, Liu W, Wang H, Yang Y-G. Vaccination with CD47 deficient tumor cells elicits an antitumor immune response in mice. Nat Commun. Springer US; 2020. 11:581.

66. https://clinicaltrials.gov/ct2/results?cond $=$ cancer\&term $=$ crisprcas $9 \&$ cntry $=\&$ state $=\&$ city $=\&$ dist $=$.

67. Ran FA, Hsu PD, Lin C-Y, Gootenberg JS, Konermann S, Trevino AE, et al. Double Nicking by RNA-Guided CRISPR Cas9 for Enhanced Genome Editing Specificity. Cell. Elsevier Inc.; 2013. 154:1380-9.

68. Guilinger JP, Thompson DB, Liu DR. Fusion of catalytically inactive Cas9 to Fokl nuclease improves the specificity of genome modification. Nat Biotechnol. 2014;32:577-82.

69. Kleinstiver BP, Pattanayak V, Prew MS, Tsai SQ, Nguyen NT, Zheng Z, et al. High-fidelity CRISPR-Cas9 nucleases with no detectable genome-wide off-target effects. Nature Nature Publishing Group. 2016;529:490-5.

70. Kocak DD, Josephs EA, Bhandarkar V, Adkar SS, Kwon JB, Gersbach CA. Increasing the specificity of CRISPR systems with engineered RNA secondary structures. Nat Biotechnol. Springer US; 2019. 37:657-66.

71. Chakrabarti AM, Henser-Brownhill T, Monserrat J, Poetsch AR, Luscombe NM, Scaffidi P. Target-Specific Precision of CRISPR-Mediated Genome Editing. Mol Cell. Elsevier Inc:; 2019. 73:699-713.e6.

72. Liu M, Rehman S, Tang X, Gu K, Fan Q, Chen D, et al. Methodologies for Improving HDR Efficiency. Front Genet. 2019. 9.

73. Gutschner T, Haemmerle M, Genovese G, Draetta GF, Chin L. Post-translational regulation of Cas9 during G1 enhances homology-directed repair. Cell Rep Elsevier Ltd. 2016;14:1555-66.

74. Li L, He Z-Y, Wei X-W, Gao G-P, Wei Y-Q. Challenges in CRISPR/ CAS9 Delivery: Potential Roles of Nonviral Vectors. Hum Gene Ther. 2015;26:452-62.

75. Nelson CE, Gersbach CA. Engineering delivery vehicles for genome editing. Annu Rev Chem Biomol Eng. 2016;7:637-62.

76. Wang $L$, Li F, Dang L, Liang $C$, Wang $C$, He B, et al. In vivo delivery systems for therapeutic genome editing. Int J Mol Sci. 2016;17:626.

77. Chandrasekaran AP, Song M, Kim K-S, Ramakrishna S. Different Methods of Delivering CRISPR/Cas9 Into Cells. Prog Mol Biol Transl Sci. 1st ed. Elsevier Inc.; 2018. p. 157-76.

78. D'Astolfo DS, Pagliero RJ, Pras A, Karthaus WR, Clevers H, Prasad V, et al. Efficient Intracellular Delivery of Native Proteins. Cell. Elsevier Inc:; 2015. 161:674-90.

79. Sun W, Ji W, Hall JM, Hu Q, Wang C, Beisel CL, et al. Self-assembled DNA nanoclews for the efficient delivery of CRISPR-Cas9 for genome editing. Angew Chemie Int Ed. 2015;54:12029-33.

80. Lee K, Conboy M, Park HM, Jiang F, Kim HJ, Dewitt MA, et al. Nanoparticle delivery of Cas9 ribonucleoprotein and donor DNA in vivo induces homology-directed DNA repair. Nat Biomed Eng. Springer US; 2017. 1:889-901.

81. Pineda M, Moghadam F, Ebrahimkhani MR, Kiani S. Engineered CRISPR systems for next generation gene therapies. ACS Synth Biol. 2017:6:1614-26.

82. Mo O. CRISPR-Cas9 human genome editing: challenges, ethical concerns and implications. J Clin Res Bioeth. 2015;06:5-7.

83. Memi F, Ntokou A, Papangeli I. CRISPR/Cas9 gene-editing: Research technologies, clinical applications and ethical considerations. Semin Perinatol. 2018. 42:487-500

84. Haapaniemi E, Botla S, Persson J, Schmierer B, Taipale J. CRISPR-Cas9 genome editing induces a p53-mediated DNA damage response. Nat Med. Springer US. 2018. 24:927-30.

85. Lessard S, Francioli L, Alfoldi J, Tardif J-C, Ellinor PT, MacArthur DG, et al. Human genetic variation alters CRISPR-Cas9 on- and off-targeting specificity at therapeutically implicated loci. Proc Natl Acad Sci. 2017;114:E11257-66.

86. Opar A. CRISPR-edited babies arrived, and regulators are still racing to catch up. Nat Med. 2019;25:1634-6.

87. Morris EC, Stauss HJ. Optimizing T-cell receptor gene therapy for hematologic malignancies. Blood. 2016;127:3305-11. 
88. Esensten JH, Bluestone JA, Lim WA. Engineering therapeutic T Cells: from synthetic biology to clinical trials. Annu Rev Pathol Mech Dis. 2017;12:305-30.

89. Shalem O, Sanjana NE, Zhang F. 99. Disrupting the Endogenous TCR Expression by TALEN and RNA-Guided Nucleases. Mol Ther. The American Society of Gene \& Cell Therapy; 2014. 22:S37.

90. Ferrara J, Reddy P, Paczesny S. Immunotherapy through T-cell receptor gene transfer induces severe graft-versus-host disease. Immunotherapy. 2010;2:791-4

91. Kamiya T, Wong D, Png YT, Campana D. A novel method to generate T-cell receptor-deficient chimeric antigen receptor T cells. Blood Adv. 2018:2:517-28.

92. Zhang Y, Mu W, Wang H. Gene editing in T cell therapy. J Genet Genomics. Elsevier Limited and Science Press; 2017. 44:415-22.

93. Knipping F, Osborn MJ, Petri K, Tolar J, Glimm H, von Kalle C, et al. Genome-wide Specificity of Highly Efficient TALENs and CRISPR/Cas9 for T Cell Receptor Modification. Mol Ther - Methods Clin Dev. Elsevier Ltd. 2017. 4:213-24.

94. Osborn MJ, Webber BR, Knipping F, Lonetree C, Tennis N, DeFeo AP, et al. Evaluation of TCR Gene Editing Achieved by TALENs, CRISPR/Cas9, and megaTAL Nucleases. Mol Ther. 2016;24:570-81.

95. Morton LT, Reijmers RM, Wouters AK, Kweekel C, Remst DFG, Pothast $C R$, et al. Simultaneous deletion of endogenous TCRa $\beta$ for TCR gene therapy creates an improved and safe cellular therapeutic. Mol Ther Elsevier Ltd. 2020;28:64-74.

96. Roybal KT, Rupp LJ, Morsut L, Walker WJ, McNally KA, Park JS, et al. Precision Tumor Recognition by T Cells With Combinatorial Antigen-Sensing Circuits. Cell. Elsevier Inc.; 2016. 164:770-9.

97. Torikai H, Reik A, Liu P-Q, Zhou Y, Zhang L, Maiti S, et al. A foundation for universal T-cell based immunotherapy: T cells engineered to express a CD19-specific chimeric-antigen-receptor and eliminate expression of endogenous TCR. Blood. 2012;119:5697-705.

98. Boardman DA, Philippeos C, Fruhwirth GO, Ibrahim MAA, Hannen RF, Cooper D, et al. Expression of a chimeric antigen receptor specific for donor HLA Class I enhances the potency of human regulatory $T$ cells in preventing human skin transplant rejection. Am J Transplant. 2017;17:931-43.

99. Jung I-Y, Kim Y-Y, Yu H-S, Lee M, Kim S, Lee J. CRISPR/Cas9-mediated knockout of DGK improves antitumor activities of human T cells. Cancer Res. 2018;78:4692-703.

100. Xu X, Gao D, Wang P, Chen J, Ruan J, Xu J, et al. Efficient homologydirected gene editing by CRISPR/Cas9 in human stem and primary cells using tube electroporation. Sci Rep. 2018;8:11649.

101. Zhang C, Peng Y, Hublitz P, Zhang H, Dong T. Genetic abrogation of immune checkpoints in antigen-specific cytotoxic T-lymphocyte as a potential alternative to blockade immunotherapy. Sci Rep. 2018. 8:5549.

102. Ren J, Liu X, Fang $C$, Jiang $S$, June $C H$, Zhao Y. Multiplex genome editing to generate universal CART cells resistant to PD1 inhibition. Clin Cancer Res. 2017:23:2255-66.

103. Ren J, Zhang X, Liu X, Fang C, Jiang S, June CH, et al. A versatile system for rapid multiplex genome-edited CART cell generation. Oncotarget. 2017;8:17002-11.

104. Anderson KG, Stromnes IM, Greenberg PD. Obstacles Posed by the Tumor Microenvironment to T cell Activity: A Case for Synergistic Therapies. Cancer Cell. Elsevier Inc.; 2017. 31:311-25.

105. Gettinger S, Choi J, Hastings K, Truini A, Datar I, Sowell R, et al. Impaired HLA class I antigen processing and presentation as a mechanism of acquired resistance to immune checkpoint inhibitors in lung cancer. Cancer Discov. 2017;7:1420-35.

106. Rupp LJ, Schumann K, Roybal KT, Gate RE, Ye CJ, Lim WA, et al. CRISPR/ Cas9-mediated PD-1 disruption enhances anti-tumor efficacy of human chimeric antigen receptor T cells. Sci Rep. 2017;7:737.

107. Kleinovink JW, Marijt KA, Schoonderwoerd MJA, van Hall T, Ossendorp F, Fransen MF. PD-L1 expression on malignant cells is no prerequisite for checkpoint therapy. Oncoimmunology. 2017;6:e1294299.

108. Eyquem J, Mansilla-Soto J, Giavridis T, van der Stegen SJC, Hamieh M, Cunanan KM, et al. Targeting a CAR to the TRAC locus with CRISPR/ Cas9 enhances tumour rejection. Nature Nature Publishing Group. 2017:543:113-7.
109. Georgiadis C, Preece R, Nickolay L, Etuk A, Petrova A, Ladon D, et al. Long terminal repeat CRISPR-CAR-coupled "universal"T cells mediate potent anti-leukemic effects. Mol Ther Elsevier Ltd. 2018;26:1215-27.

110. Hu B, Zou Y, Zhang L, Tang J, Niedermann G, Firat E, et al. Nucleofection with Plasmid DNA for CRISPR/Cas9-Mediated Inactivation of Programmed Cell Death Protein 1 in CD133-Specific CART Cells. Hum Gene Ther. 2019:30:446-58.

111. Shao J, Xu Q, Su S, Meng F, Zou Z, Chen F, et al. Engineered cells for costimulatory enhancement combined with IL-21 enhance the generation of PD-1-disrupted CTLs for adoptive immunotherapy. Cell Immunol Elsevier. 2017;320:38-45.

112. Friedman KM, DeVillier LE, Feldman SA, Rosenberg SA, Dudley ME. Augmented lymphocyte expansion from solid tumors with engineered cells for costimulatory enhancement. J Immunother. 2011;34:651-61.

113. Walseng E, Köksal H, Sektioglu IM, Fåne A, Skorstad G, Kvalheim G, et al. A TCR-based chimeric antigen receptor. Sci Rep. 2017;7:10713.

114. Bueno C, Velasco-Hernandez T, Gutiérrez-Agüera F, Zanetti SR, Baroni ML, Sánchez-Martínez D, et al. CD133-directed CAR T-cells for MLL leukemia: on-target, off-tumor myeloablative toxicity. Leukemia. Springer US. 2019. 33:2090-125.

115. Nguyen DH, Ball ED, Varki A. Myeloid precursors and acute myeloid leukemia cells express multiple CD33-related Siglecs. Exp Hematol. 2006;34:728-35.

116. https://clinicaltrials.gov/ct2/results? cond $=$ AML\&term $=C D 33+C A R+$ $T+$ cells\&cntry $=\&$ state $=\&$ city $=\&$ dist $=\&$ phase $=4 \&$ phase $=0 \&$ phase $=1$.

117. John S, Chen H, Deng M, Gui X, Wu G, Chen W, et al. A novel Anti-LILRB4 CAR-T cell for the treatment of monocytic AML. Mol Ther Elsevier Ltd. 2018;26:2487-95.

118. Kim MY, Yu K-R, Kenderian SS, Ruella M, Chen S, Shin T-H, et al. Genetic Inactivation of CD33 in Hematopoietic Stem Cells to Enable CART Cell Immunotherapy for Acute Myeloid Leukemia. Cell. Elsevier Inc. 2018. 173:1439-1453.e19.

119. Borot F, Wang H, Ma Y, Jafarov T, Raza A, Ali AM, et al. Gene-edited stem cells enable CD33-directed immune therapy for myeloid malignancies. Proc Natl Acad Sci. 2019;116:201819992.

120. Gomes-Silva D, Atilla E, Atilla PA, Mo F, Tashiro H, Srinivasan M, et al. CD7 CART cells for the therapy of acute myeloid leukemia. Mol Ther Elsevier Ltd. 2019;27:272-80.

121. Ormhøj M, Scarfò I, Cabral ML, Bailey SR, Lorrey SJ, Bouffard AA, et al. Chimeric antigen receptor $T$ cells targeting CD79b show efficacy in lymphoma with or without cotargeting CD19. Clin Cancer Res. 2019;25:7046-57.

122. Newick K, O'Brien S, Moon E, Albelda SM. CART cell therapy for solid tumors. Annu Rev Med. 2017;68:139-52.

123. Hu W, Zi Z, Jin Y, Li G, Shao K, Cai Q, et al. CRISPR/Cas9-mediated PD-1 disruption enhances human mesothelin-targeted CART cell effector functions. Cancer Immunol Immunother. Springer Berlin Heidelberg; 2018.

124. Su S, Zou Z, Chen F, Ding N, Du J, Shao J, et al. CRISPR-Cas9-mediated disruption of PD-1 on human T cells for adoptive cellular therapies of EBV positive gastric cancer. Oncoimmunology. 2017;6:e1249558.

125. Guo X, Jiang H, Shi B, Zhou M, Zhang H, Shi Z, et al. Disruption of PD-1 enhanced the anti-tumor activity of chimeric antigen receptor $T$ cells against hepatocellular carcinoma. Front Pharmacol. 2018;9:1-15.

126. Choi BD, Yu X, Castano AP, Darr H, Henderson DB, Bouffard AA, et al. CRISPR-Cas9 disruption of PD-1 enhances activity of universal EGFRvIII CART cells in a preclinical model of human glioblastoma. J Immunother Cancer. 2019. 7:304.

127. Nakazawa T, Natsume A, Nishimura F, Morimoto T, Matsuda R, Nakamura M, et al. Effect of CRISPR/Cas9-Mediated PD-1-disrupted primary human third-generation CAR-T cells targeting EGFRvIll on in vitro human glioblastoma cell growth. Cells. 2020;9:998.

128. Tang N, Cheng C, Zhang X, Qiao M, Li N, Mu W, et al. TGF- $\beta$ inhibition via CRISPR promotes the long-term efficacy of CAR T cells against solid tumors. JCl Insight. 2020.5.

129. Marotte L, Simon S, Vignard V, Dupre E, Gantier M, Cruard J, et al. Increased antitumor efficacy of PD-1-deficient melanoma-specific human lymphocytes. J Immunother Cancer. 2020;8:e000311.

130. Qin H, Ramakrishna S, Nguyen S, Fountaine TJ, Ponduri A, Stetler-Stevenson $\mathrm{M}$, et al. Preclinical development of bivalent chimeric antigen 
receptors targeting both CD19 and CD22. Mol Ther Oncolytics. Elsevier Ltd. 2018;11:127-37.

131. Bonaventura P, Shekarian T, Alcazer V, Valladeau-Guilemond J, ValsesiaWittmann S, Amigorena S, et al. Cold Tumors: A Therapeutic Challenge for Immunotherapy. Front Immunol. 2019. 10.

132. Deng H, Tan S, Gao X, Zou C, Xu C, Tu K, et al. Cdk5 knocking out mediated by CRISPR-Cas9 genome editing for PD-L1 attenuation and enhanced antitumor immunity. Acta Pharm Sin B Elsevier Ltd. 2020;10:358-73.

133. Tu K, Deng H, Kong L, Wang Y, Yang T, Hu Q, et al. Reshaping tumor immune microenvironment through acidity-responsive nanoparticles featured with CRISPR/Cas9-mediated programmed death-ligand 1 attenuation and chemotherapeutics-induced immunogenic cell death. ACS Appl Mater Interfaces. 2020;12:16018-30.

134. Wucherpfennig KW, Cartwright ANR. Genetic screens to study the immune system in cancer. Curr Opin Immunol Elsevier Ltd. 2016;41:55-61.

135. Marquardt S, Solanki M, Spitschak A, Vera J, Pützer BM. Emerging functional markers for cancer stem cell-based therapies: Understanding signaling networks for targeting metastasis. Semin Cancer Biol Elsevier Ltd. 2018;53:90-109.

136. Shifrut E, Carnevale J, Tobin V, Roth TL, Woo JM, Bui CT, et al. Genomewide CRISPR Screens in Primary Human T Cells Reveal Key Regulators of Immune Function. Cell. 2018. 175:1958-1971.e15.

137. Pan D, Kobayashi A, Jiang P, Ferrari de Andrade L, Tay RE, Luoma AM, et al. A major chromatin regulator determines resistance of tumor cells to T cell-mediated killing. Science (80-). 2018:359:770-5.

138. Wei J, Long L, Zheng W, Dhungana Y, Lim SA, Guy C, et al. Targeting REGNASE-1 programs long-lived effector T cells for cancer therapy. Nature. 2019. 576:471-6.

139. Li F, Huang Q, Luster TA, Hu H, Zhang H, Ng W-L, et al. In vivo epigenetic CRISPR screen identifies Asf1a as an immunotherapeutic target in Krasmutant lung adenocarcinoma. Cancer Discov. 2020;10:270-87.

140. Crowther MD, Dolton G, Legut M, Caillaud ME, Lloyd A, Attaf M, et al. Genome-wide CRISPR-Cas9 screening reveals ubiquitous T cell cancer targeting via the monomorphic MHC class I-related protein MR1. Nat Immunol. 2020. 21:178-85.

141. Sterner RM, Sakemura R, Cox MJ, Yang N, Khadka RH, Forsman CL, et al. GM-CSF inhibition reduces cytokine release syndrome and neuroinflammation but enhances CAR-T cell function in xenografts. Blood. 2019;133:697-709

142. Schröder M, Krötschel M, Conrad L, Naumann SK, Bachran C, Rolfe $A$, et al. Genetic screen in myeloid cells identifies TNF-a autocrine secretion as a factor increasing MDSC suppressive activity via Nos2 upregulation. Sci Rep. 2018:8:13399.
143. Wang R, Liu Y, Liu L, Chen M, Wang X, Yang J, et al. Tumor cells induce LAMP2a expression in tumor-associated macrophage for cancer progression. EBioMedicine. 2019. 40:118-34.

144. Sheng W, LaFleur MW, Nguyen TH, Chen S, Chakravarthy A, Conway $J R$, et al. LSD1 Ablation Stimulates Anti-tumor Immunity and Enables Checkpoint Blockade. Cell. Elsevier Inc.; 2018. 174:549-563.e19.

145. Janse van Rensburg HJ, Azad T, Ling M, Hao Y, Snetsinger B, Khanal P, et al. The Hippo Pathway Component TAZ Promotes Immune Evasion in Human Cancer through PD-L1. Cancer Res. 2018. 78:1457-70.

146. Magnuson AM, Kiner E, Ergun A, Park JS, Asinovski N, Ortiz-Lopez A, et al. Identification and validation of a tumor-infiltrating Treg transcriptional signature conserved across species and tumor types. Proc Natl Acad Sci. 2018;115:E10672-81.

147. Kearney CJ, Vervoort SJ, Hogg SJ, Ramsbottom KM, Freeman AJ, Lalaoui $\mathrm{N}$, et al. Tumor immune evasion arises through loss of TNF sensitivity. Sci Immunol. 2018. 3:eaar3451.

148. Blaeschke F, Willier S, Stenger D, Lepenies M, Horstmann MA, Escherich $\mathrm{G}$, et al. Leukemia-induced dysfunctional TIM-3 + CD4 + bone marrow $T$ cells increase risk of relapse in pediatric B-precursor ALL patients. Leukemia. Springer US; 2020; http://dx.doi.org/10.1038/s41375-020-0793-1.

149. Felce SL, Anderson AP, Maguire S, Gascoyne DM, Armstrong RN, Wong KK, et al. CRISPR/Cas9-Mediated Foxp1 Silencing Restores Immune Surveillance in an Immunocompetent A20 Lymphoma Model. Front Oncol. 2020;10:1-14.

150. Dufva O, Koski J, Maliniemi P, lanevski A, Klievink J, Leitner J, et al. Integrated drug profiling and CRISPR screening identify essential pathways for CART-cell cytotoxicity. Blood. 2020;135:597-609.

151. https://osp.od.nih.gov/wp-content/uploads/2016/08/1524_RAC_ Briefing_Slides.pdf. https://osp.od.nih.gov/wp-content/uploa ds/2016/08/1524_RAC_Briefing_Slides.pdf.

152. Baylis F, McLeod M. First-in-human Phase 1 CRISPR Gene Editing Cancer Trials: Are We Ready? Curr Gene Ther. 2018;17:309-19.

153. Baylis F. Counterpoint: the potential harms of human gene editing using CRISPR-Cas9. Clin Chem. 2018;64:489-91.

154. Postow MA, Sidlow R, Hellmann MD. Immune-Related Adverse Events Associated with Immune Checkpoint Blockade. Longo DL, editor. N Engl J Med. 2018;378:158-68.

155. Wang K, Han Y, Cho WC, Zhu H. The rise of human stem cell-derived natural killer cells for cancer immunotherapy. Expert Opin Biol Ther. Taylor \& Francis. 2019;19:141-8.

\section{Publisher's Note}

Springer Nature remains neutral with regard to jurisdictional claims in published maps and institutional affiliations. 